\title{
HEALTH CARE SERVICES MARKETING OF SWEDISH INNOVATION - A COMPARATIVE STUDY
}

\author{
Akmal S. Hyder, University of Gävle, Sweden \\ Maria Fregidou-Malama, University of Gävle, Sweden
}

\begin{abstract}
This paper deals with a comparative study between Brazil, China and Philippines on services marketing. By focusing on culture, standardization/adaptation, trust and network, attempt is made to illustrate how impact of service characteristics can be handled to smooth marketing of health care services internationally. Data has been collected through face-to-face semi-structured interviews with 21 respondents from Brazil, China, Philippines and Sweden. The result shows that culture has much effect on the operations of Elekta Philippines and China while Brazilian establishment is run by following general marketing practices. Standardization has been common regarding treatment and service quality but some adaptation has taken place in Philippines to treat new diseases not included in the Gamma knife tradition. Trust is found necessary in all the cases but has been built in different ways. In China, guanxi has been used to develop informal relationships with the customers to ensure trust. Trust in Philippines is developed by recruiting relatives and friends and relying on experience in work with old Gamma knife facility. In Brazil, long-term relationships with the customers have been stressed and are built on understanding, business facts, competence and customers' access to Elekta reference centers.
\end{abstract}

\section{INTRODUCTION}

This paper deals with a comparative study between Brazil, China and Philippines on services marketing. By focusing on culture, standardization/adaptation, trust and network, attempt is made to illustrate how impact of service characteristics can be handled to smooth marketing of health care services internationally.

Hyder \& Fregidou-Malama (2009) identified that heterogeneity and tangibility make the services difficult for customers to understand what they really buy and consume. Further differences in culture make the marketing complicated if the service is sold in other countries. Researchers find it difficult how to study services when they are seldom available for demonstration and description, particularly in the international market. In many service sectors including health care, offering of services needs equipment support for creating, designing and delivering services. International marketing of such a service confronts therefore with a number of complications comprising of service characteristics, cultural differences, and use of equipments and support elements to guarantee expected values to the customers. Research is needed to highlight how sales of complicated services are planned, organized and conducted in the international market.

Standardization/adaptation has always been a significant issue in the development of international marketing strategy (Erdogomus et al. 2010). Knowing the local market is essential for developing a solid marketing strategy and therefore firms need to have right contacts in the market. Networking is significant in international marketing where the customers are different, economical and social environment poses various challenges and political and regulatory bodies either make the business easy or difficult (Fregidou-Malama and Hyder 2011). Network is helpful to develop trust when the marketing firm possesses a large cultural aloofness from the host country. Ford (2002) notes that relationships and networks are important to build trust and thereby to reduce the effects of cultural distance. Thus, standardization/adaptation, network and trust are interconnected and can largely solve the problems of cultural differences in international services marketing.

Elekta is a Swedish health care company which has been engaged since a long time in innovating and marketing clinical solutions for cancer and brain disorders around the world. It is the world leader in its field and has succeeded developing customer friendly equipments for offering necessary treatments. In this study, we have gone into the depth of Elekta's marketing process and explore how this health care service is indeed marketed in different countries. We compare how the Swedish company market health care services in Brazil, China and Philippines by utilizing standardization/adaptation, network and trust. In concrete, the following two questions are addressed in this paper:

- How do standardization/adaptation, network and trust take place in relation to service characteristics and affect marketing of health care services in Brazil, China and Philippines?

- How does Elekta deal with the local cultures to facilitate marketing of health care services in those countries? 


\section{CONCEPTUAL FRAMEWORK}

The theoretical section, which is based on Fregidou-Malama and Hyder (2011), is comprised of standardization/adaptation, network and trust in presence of cultural differences. The ultimate goal of the framework is to demonstrate how the service characteristic barriers can be handled in international marketing by using the above variables.

In international business literature, cultural awareness is frequently discussed to ease the marketing process (Daniels et al. 2009). Cultural awareness is the understanding that there are many cultures and subcultures, and each such culture can influence the business activities conducted in that environment. By studying different cultures, Hofstede (1991) identified four dimensions of culture, namely power distance, individualism, masculinity and uncertainty avoidance. Power distance accepts that there is inequality in the society. Individualism treats people as individualists while collectivism describes people as integrated, coherent groups. Masculinity upholds masculine characteristics such as earnings and advancement while femininity defends opposite values such as friendliness and caring. Uncertainty avoidance indicates the degree of uncertainty, a society perceives due unknown and uncertain situations.

When going and operating abroad, firms face the challenge of finding the optimal balance between standardizing and adapting the marketing strategies across national borders in order to be successful (Schmid and Kotulla 2011). Standardization/adaptation has always been a critical issue in international marketing. Adaption/standardization does not necessarily apply to the whole product/service but usually deals with some part of it such as pricing, sales reduction, promotion, distribution and packaging (Fregidou-Malama 2011). Network tells how the firms are interconnected with the different actors in the market to secure necessary resource for conducting firms' activities. Ritter et al. (2004) recognize that firms are embedded in a network of ongoing business and non-business relationships that both enable and constraint the firm's performance. All relationships are therefore not equally important depending on their contribution vital to the core activities of the firms. Trust is seen as an important factor for the development of a successful long-term business relationship (Ford 2004: Madhok 2006). To build trust, there is a necessity from both partners that they are willing to engage in such a relationship. We anticipate that importance of trust, and process and technique for developing trust can vary from culture to culture. A comparative study is helpful to validate whether cultural differences have some impact on trust building and implication of trust.

Zeithaml et al. (2006) describe four characteristics, i.e. intangibility, perishability, simultaneous production and heterogeneity of services which make the procurement and marketing complex. Managers have to take a lot of trouble to handle these complexities so that right message is communicated to the customers. Hyder and Fregidou-Malama (2009) have studied service firm characteristics and identified intangibility and heterogeneity as the major obstacles for marketing of international services. We also treat these variables relevant for this study and focus how these obstacles can be dealt with in relation to standardization/adaptation, network and trust between different cultures.

\section{METHODOLOGICAL DISCUSSION}

As this work is engaged in theory building by a comparative study, case study research is found suitable (Eisenhardt 1989). For data collection, qualitative method is employed to guarantee the richness of data to study services marketing in culturally distant environments. Referring Cheng (2007), Doz (2011) observe that qualitative research may be essential for surfacing contex tual dimensions in international business, such as differences between countries. Variables like trust, networking and culture are complex and interrelated which needs a researcher to go into the depth of the real world situation and explore how and why things happen and do not happen. Qualitative methodology is primarily directed to understanding the complex and the elusive in a systematic perspective more than to establish unambiguous cause and effect relationships between single variables (Gummesson 2005).

A large number of interviews had been conducted with host country executives, host country professionals, and executives of Elekta in Sweden. In the Chinese case, Elekta marketing manager for Asia and Elekta China manager were interviewed. The second interview was conducted in Chinese and then translated to English by the Chinese interviewee. The Philippine case was based on five interviews including president and Clinic Director of the Elekta center in Philippines. For the Brazilian case, we interviewed 14 people including executives and professionals both in Brazil and Sweden. Two interviews were conducted in Swedish which were translated into English by the researchers. All interviews were face-to-face and lasted between 30 minutes to three hours. Interviews were semi-structured and tape-recorded. Besides interviews observations had been made in Elekta premises in Sweden, Philippines and Brazil. Six visits have been made to Gamma knife center in Philippines to examine how the treatments proceeded and the services offered. In Brazil, the researchers stayed in the Elekta office for a week to interview the 
personnel and closely watch the daily works and dealing with the customers. The researchers also visited the two hospitals at São Paulo, one of which is equipped with newly bought six Elekta machines, to see working environment and also talk with technicians and physicians. No such observation could be conducted at the Elekta China as no visit could be made to the Gamma knife center. Using different sources for this type of exploratory study has been emphasized by Yin (2003). By following the conceptual framework, data were reduced inductively to conduct the comparative analysis.

\section{THE CASE STUDIES}

\section{Elekta Brazil}

In 2007, Elekta established a wholly-owned health care company in São Paulo. The company employs 41 persons and all of them are local people. Keeping contact with the authorities and show respect to the government hierarchy is duly practiced by the company to ease the use of nuclear power in the operation. Power distance is visible in the company as the employees are mentally dependent on the local manager for guidance, support and management of the company. However trust on the local manager is also substantial as he came from the main competitor, established the Swedish subsidiary from scratch and is well known to the customers for his long presence the in Brazilian neuroscience market.

Customers are very sensitive in their contacts with Elekta. If they call, company personnel has to respond immediately, not really to solve the problem but for honor and showing importance to the customer. The local culture suggests that one cannot keep the customers waiting because it deals more with the customers' prestige than doing the pure business. Elekta Brazil stresses the importance of having the right employees. The local employees are cheaper compared to foreigners and they speak Portuguese, the native language, English and Spanish. Since its inception, Elekta Brazil hired key employees from the American competitors to acquire a major market share. Elekta Brazil helps the customers, who are medical doctors and hospitals, with the installation of the healthcare equipment. It organizes training of the employees at different gamma Knife (Elekta's one of the major equipments for treatment of cancer and brain disorders by radiation therapy) centers in Brazil and other countries and offers after sale services and necessary technical support.

The company adapts equipments to the customer's requirements and provides upgrading of the offerings for at least 15 years. It largely follows the guidance of the head office at Stockholm. The ad messages are translated into Portuguese but adaptation is made with the colors and images to bring life to them. The company develops informal relations with hospitals, universities and doctors in Brazil. It participates in meetings that are organized by Leksell Gamma Knife society and sends its employees for training in countries around the world where reference centers are established. To develop trust, Elekta Brazil works to establish a similar reference center in São Paulo in the near future. Elekta is expecting to use this center for building trust and support business expansion in Brazil and other Latin American countries through demonstration of the equipments and services. By offering all necessary information, after sales services and technical support, Elektra Brazil tries to gain trust from the customers. Compared to the main American competitor, Elekta management's openness to the Brazilian subsidiary and local empowerment helped to develop trust in two fronts: within the employees of the local company and in relationship between the customers and the employees.

In marketing, Elekta Brazil focuses on clients and their needs. Even cost of treatment and level of technology are considered for acquiring business. The company recently established a neurosurgery centre at São Paolo with six huge Elekta machines as a sign of its professionalism and ongoing contacts with the authority. Major reasons for getting this business are said to be competitive price, perfect equipments offering synergies, customer friendly software programs, after sales services, satisfactory demonstration of equipments in different reference centers and emphasizing total solution for the customers.

\section{Elekta Philippines}

In 1997, Dr. Eduardo Mercado together with friends and other doctors, established Gamma Knife center which is the first and the only Gamma Knife facility in the Philippines. For financing the project, an independent corporation under the armed forces of the Philippines, was involved in the company as a partner along with the neuro-physicians. To spread knowledge about the centre, free treatment had been initially offered to soldiers who needed this treatment. The first doctors were trained in Gamma Knife centers in Sweden, and Germany. To counter problems with old traditions in Philippines, the company introduced the Leksell Gamma Knife through lectures, newspaper articles and journal articles. Word-of-mouth recommendations by satisfied patients and doctors helped to establish its reputation. To recruit the employee, Elekta Philippines use personal relations for 
recruitment. Majority of the employees are related to each other. More emphasis has been given on personal liking and acquaintance than competence. This is a sign of collectivism and uncertainty avoidance which is based on trust.

The company adapts the prices based on the financial capacity of the patients. To live up to the promised standard the doctors act with a Western attitude in respect of time, management and professionalism, which help to develop trust in the local market. But the old machine has been a point of criticism from the competitors and the local physicians. The machine underwent little upgrading in its lifetime and thereby became difficult for the center to offer a worldwide standard service to the clients. The advanced technology applied in the new machine and its high price are not found justified by the management for the Philippines market. New training by Elekta has therefore not been necessity as the local physicians could handle the treatment well and also succeeded to make some adaptations of the Gamma knife machine to keep it functioning after a period of 15 years. The doctors claim that through local adaptation and long experience, they can still offer a quality service to the patients.

Informal relationships with medical schools and hospitals spread positive information about the center. It offers medical students internships which gives Elekta Philippines recognition in the local society. In addition to regular treatments it also uses the equipments for treating Parkinson, dystopia and some other diseases. Being a member of Leksell Gamma Knife Society, Elekta Philippines shares information, experiences, clinical techniques and advances in scientific research with the co-users.

\section{Elekta China}

Elekta China is located in Shanghai and was established in 2000. It is responsible for selling linear accelerators and Leksell Gamma Knife solutions and has about 300 employees. Elekta China strictly follows licensing and guaranty requirements of China. The company recruits local employees and it is run through a joint venture. Elekta China maintains standardization on service quality, technology and training system for the doctors and other employees. China has been a difficult market as locally produced Gamma knife machine, which is a less quality equipment, is sold at lower price in the local market. Further attempts have been made by the local competitors to damage the reputation of the Swedish company through false campaigns. Elekta China did not compromise with the quality and maintained its high price throughout. It was difficult in the beginning but the market has gradually accepted that quality has a price and it is particular important when it relates to live saving medical treatment. Adaptation is made to follow the legal restrictions and health care policies of the government.

The company develops network relationships with the local government and customers and exchange experience by organizing and participating in customers meetings. Leksell Gamma Knife Society gives the company access to publications and contacts with other hospitals. Due to the presence of high power distance and collectivism in the local country, Elekta China cares about local traditions, rules and also tries to find the right persons for developing vital contacts. It has built Guanxi, a Chinese pattern of relationship, with the government and authorities to enter the Chinese market. Communication and relationships in the local market helps the company to develop an understanding and acceptance for Elektra's solutions. Elekta has developed an innovative platform by the name "society meetings" for external networking where current and potential customers can meet and share information on clinical techniques, treatment results, advanced scientific research related on Leksell Gamma knife. Elekta China sees it as a great opportunity to establish contact with other customers and develop their competence through dialog and sharing of experience. Even society meetings serve Chinese hospitals to getting international contacts and access to publications on neuroscience technology.

Sweden and other west European countries are well known in China for offering quality products and services. Swedish country of origin has contributed much to build corporate reputation and this reputation has further helped Elekta China to develop its marketing strategy based on consistency in quality, advanced technology, training and technical support to the customers and after sales services. The argument of quality worked well as the service dealt with health care and applies to serious diseases like cancer and brain tumor. The word-of-mouth has been important for it to develop and maintain trust in the local market. Elekta China usually refers potential clients to the old patients who had been successfully treated by the company.

\section{CASE COMPARISON}

Trust and network development have been found essential to fit with the cultural environment of all the three countries. Role of culture was dominant in China and Philippines and therefore Elekta companies had to understand how culture affects relationships and also to find out the major actors in those markets. However the cultural features have been manifested differently in these two countries. Collectivism and uncertainty avoidance were evident in Philippines as the company relied on kinship for employing people mainly to keep control within the owner group and secure trust. Relying on old equipment 
shows that the company is not willing to bring changes which is a mark of traditional thinking, highly linked with power distance as suggested by Hofstede (1991). In the Chinese case, guanxi is developed to follow the long Chinese tradition that belongs to collectivism and power distance. Sense of professionalism was found in Elekta Brazil that concentrated on acquiring marketing competence and penetrating the competitors' market share. Cultural view was present in recruiting local people for easy communication with the customers. This attribute can also be related to pragmatic business thinking by Elekta Brazil. Over confidence and respect to the local manager by the Brazilian employees however show that power dependence is present in the company. A comparison between the Elekta companies is presented in Table 1.

Standardization of the service concept and training programs helped the companies to develop trustful and homogenous environments in all the three cases. The work of Elekta Brazil was rigorous as it was actively marketing Elekta solutions within and outside Brazil. It was relatively new entrant in the Brazilian market and had to compete with the already established and well-known American competitor. The marketing was in fact aggressive and contains features of both standardization and adaptation. Concerning technology and equipment, the company applied standard solution package comprising accurate quality, supporting soft ware programs, training, access to research information on neurological treatment and full time technical support. The local company was empowered to take decisions on matters relating to marketing, using own ads, visiting customers and conducting deals with the customers on behalf of Elekta Sweden. Some adaptations were allowed in connection to financing of certain projects considering the merit of the potential customers. In Elekta Philippines, adaptations were made to follow the local tradition and also offering treatments of local diseases not originally covered by the Gamma knife practice. Development of relationships in Chinese style was a successful adaptation in the Chinese case.

The problem of intangibility was overcome by country of origin, training, after sale services and technical support. For Elekta Brazil, reference centers played an important role in this regard. Trust and informal relationships were found effective in China and Philippines to reduce the effect of heterogeneity. Guanxi, which was deeply rooted in the Chinese culture, required the company to indentify the right actors for building relationships. Special care had been taken by the local employees to keep conformity with this local tradition. For Elekta Philippines, trust on the employees was deemed important to offer consistent services. However more emphasis was given on the acquaintance than competence of the employees. It can also partly explain why the company concentrated on the old equipment and didn't show interest in upgrading or acquiring a modern equipment. For developing trust, Elekta Brazil relied on usual marketing practices including keeping continuous contact with the customers before and after the business deals, providing all necessary documents and technical support, offering training to the technicians and physicians and often visiting hospitals. The trust in this case was built on understanding, dialog and the customers' belief on the availability of the support from Elekta Brazil whenever needed.

\section{CONCLUSIONS}

This study shows that both adaptation and standardization are practiced by the Elekta companies in the studied countries. Adaptation relates mainly to marketing, pricing and building informal relationships. Cultural adaptation has been particularly important in China which is manifested in the development of Guanxi. Standardization is associated with the service concept and training, and is practiced in all the Elekta companies. Maintenance of standardization in the core area has served two purposes: offered uniformity in the delivery of services and evoked trust on quality to the customers and the local employees. This finding suggests that some standardization is not an option but a necessity to communicate with the markets. The message should be clear that the company does not compromise with the concept but responds positively to adaptation when it is important for the country. Hiring on personal relationship in Philippines is an example of how trust is developed and ensured in the company. But it also shows that how the management is influenced by the culture and no fruitful attempt is made to develop competence based working force. Professionalism is evident in Elekta Brazil and adaptation and standardization have been successfully combined to offer betters services to the customers and be highly competitive in the market.

This research work suggests that internationalization of health care service needs a manager's sensitiveness to cultural differences and competence to properly combine standardization with adaptation. To make the service tangible, it is also important that the service is appropriately demonstrated to the customers which Elekta Brazil has done by organizing visits to reference centers where Elekta equipments are in use. Another important issue is the type of offering made to the customer. As the technology is complicated and central in health care service, managers need to come up with a package of total solution. Certainly it is expensive for customers, but it is again the task of the manager to find a reasonable solution for the customer. In one case Elekta Brazil came in contact with a prospective buyer who had difficulty to arrange financing. The company took the matter seriously and consulted with the Stockholm office to find out a solution. The matter was solved by the help empathy 
and broader perspective of the Brazilian management. Only emphasizing the local culture cannot work in the long run, is demonstrated by Elekta Philippines. The company has not undergone any upgrading and further lacked the vision of recruiting efficient employees and relied on the relatives of the doctors and owners of the company.

One limitation of the study is the small number of cases. By including few more cases, the result can be further generalized. We have looked on the culture from a broad perspective, a detail study on culture relating to different aspect of internationalization could therefore provide important insight of services marketing. Further, impact of service characteristics on health care can also be compared within the same country to keep away the role of culture.

\section{REFERENCES}

Cheng, J.L.C. (2007). Critical issues in international management research: An agenda for future advancement. European Journal of International Management, 1, 23-38.

Daniels, J.D., Radebaugh, L.H. \& Sullivan, D.P. (2009). International business - Environments and operations. New Jersey: Pearson-Prentice Hall.

Doz, Y. (2011). Qualitative Research for International Business. Journal of International Business Studies, 42, 582-590.

Eisenhardt, K.M. (1989). Building theories from Case study research. Academy of Management Review, 14(4): 532-550.

Erdogmus, I.E., Bodur, M. \& Yilmaz, C. (2010). International strategies of emerging market firms - Standardization in brand management revisited. European Journal of Marketing, 44, 1410-1436.

Ford, D. (2004). Guest Editorial. International Marketing Review, 21, 139-141.

Ford, D. (2002). The development of buyer-seller relationships in industrial markets. In D. Ford (Ed.), Understanding business marketing and purchasing. Australia: Thomson Learning.

Fregidou-Malama, M. \& Hyder, A.S. (2011). Health services marketing in a cross-cultural environment: Gamma knife in Brazil. The impact of globalization on networks and relationship dynamics, $27^{\text {th }}$ IMP conference, 31 August -3 September. UK: University of Strathclyde.

Gummesson, E. (2005). Qualitative research in marketing - Road-map for a wilderness of complexity and unpredictability. European Journal of marketing, 39, 309-327.

Hofstede, G. (1991). Cultures and organizations: Software of the mind. London: McGraw-Hill Book Company.

Hyder, A. S. \& Fregidou-Malama, M. (2009). Services marketing in a cross-cultural environment: The case of Egypt. Journal of Services Marketing, 23, 261-271.

Lages, L.F., Abrantes, J.L. \& Lages, C.L. (2008). The STARTADAPT scale - A measure of marketing strategy adaptation to international business markets. International Marketing Review, 25, 584-600.

Madhok, A. (2006). How much does ownership really matter? Equity and trust relations in joint venture relationships. Journal of International Business Studies, 37, 4-11.

Ritter, T., Wilkinson, I.F. \& Johnston, W.J. (2004). Managing in complex business networks. Industrial Marketing Management, 33, 175-183.

Schmid, S. \& Kotulla, T. (2011). 50 years of research on international standardization and adaptation - From a systematic literature analysis to a theoretical framework. International Business Review, 20, 491-507.

Yin, R.K. (2003). Case study research - Design and methods. Thousand Oaks: Sage Publications. 
Zeithaml, V.A., Bitner, M.J. and Gremler, D.D. (2006). Services marketing: Integrating customer focus across the firm. Boston: McGraw-Hill.

Table 1 Comparison of Elekta's business between Brazil, Philippines and China

\begin{tabular}{|c|c|c|c|}
\hline Variables & Brazil & Philippines & China \\
\hline Culture & $\begin{array}{l}\text { Power distance and } \\
\text { individualism affect } \\
\text { the business. }\end{array}$ & $\begin{array}{l}\text { Power distance, collec- } \\
\text { tivism \& uncertainty } \\
\text { avoidance affect the } \\
\text { business. }\end{array}$ & $\begin{array}{l}\text { Guanxi is stressed as a } \\
\text { part of collectivistic } \\
\text { society. Power distance } \\
\text { important in developing } \\
\text { relationship. }\end{array}$ \\
\hline $\begin{array}{l}\text { Standardi- } \\
\text { zation }\end{array}$ & $\begin{array}{l}\text { Service concept } \\
\text { standardized. } \\
\text { Country of origin }\end{array}$ & $\begin{array}{l}\text { Service quality \& } \\
\text { training of doctors } \\
\text { standardized. }\end{array}$ & $\begin{array}{l}\text { Identical product is } \\
\text { stressed with consistent } \\
\text { service quality. }\end{array}$ \\
\hline Adaptation & $\begin{array}{l}\text { Marketing adaptation } \\
\text { in response to local } \\
\text { culture. }\end{array}$ & $\begin{array}{l}\text { Terms of payment } \\
\text { adapted to local } \\
\text { financial situation. } \\
\text { Hiring on personal } \\
\text { relationship. }\end{array}$ & $\begin{array}{l}\text { Cultural adaptation made } \\
\text { to reduce communication } \\
\text { gap. Extra long warranty } \\
\text { granted to meet the local } \\
\text { Country demand. }\end{array}$ \\
\hline Network & $\begin{array}{l}\text { Formal \& informal } \\
\text { contact present. } \\
\text { Informal contact } \\
\text { essential for } \\
\text { building trust. }\end{array}$ & $\begin{array}{l}\text { Formal network with } \\
\text { Doctors, medical centers } \\
\text { \& students. Informal } \\
\text { network important in the } \\
\text { local culture. }\end{array}$ & $\begin{array}{l}\text { Informal network relates } \\
\text { to local sales, marketing } \\
\text { and R\&D. Building } \\
\text { better guanxi with the } \\
\text { government significant. }\end{array}$ \\
\hline Trust & $\begin{array}{l}\text { Adaptation helpful } \\
\text { for trust development. } \\
\text { Network and trust } \\
\text { Interrelated. }\end{array}$ & $\begin{array}{l}\text { Long presence in the } \\
\text { market. Involvement in } \\
\text { neurosurgeon training } \\
\text { makes the firm trustworthy. }\end{array}$ & $\begin{array}{l}\text { Country of origin, } \\
\text { reputation and word-of } \\
\text {-mouth lead to creating } \\
\text { trust. }\end{array}$ \\
\hline
\end{tabular}

